\title{
Spontaneous Aortic Lesions in Marine Turtles
}

\author{
Takayoshi Toda, Yumiko Toda and Fred A. Kummerow \\ Burnsides Research Laboratory, University of Illinois, \\ Urbana, IL 61801 and Harlan E. Moore Heart Research \\ Foundation, 503 South Sixth St., Champaign, IL 61820, \\ USA
}

Toda, T., Toda, Y. and Kummerow, F.A. Spontaneous Aortic Lesions in Marine Turtles. Tohoku J. exp. Med., 1984, 144 (2), 139-142 ——Marine turtles were found to have gross aortic aneurysmal dilations and multiple, raised grayishwhite plaques which resembled both the aortic lesions of Marfan's syndrome in humans and those induced by chemical manipulation in animals. Smooth muscle cells in these aortic lesions displayed considerable functional as well as morphological similarity in their response to environmental injury in both turtles and humans. - marine turtle; aortic lesion

Various animal models have been used for experimental atherosclerosis research. There are different levels of susceptibility to atherogenic regimens among different species. A study of spontaneous arteriosclerosis in different animal species is important in that it may offer clues to the pathogenesis of human atherosclerosis. However, few studies have explored this point. In a previous study, we have explained the differences in aortic medial structures in various animal species (Toda et al. 1984). An attempt has been made in this communication to describe aortic lesions of marine turtles from a phylogenetic viewpoint.

\section{Materials and Methods}

Aortas from thirteen, six month-old green sea turtles (Chelonia mydas) were collected at the Turtle Farm, Grand Cayman Island, at the time of slaughter. The tissues collected for electron microscopy were fixed in $1.4 \%$ phosphate buffered glutaraldehyde and post-fixed in $1 \%$ osmium tetroxide. The specimens were dehydrated with increasing concentrations of ethanol and embedded in EM bed 812 epoxy resin. Ultrathin sections were cut, stained with uranyl acetate and lead citrate and examined by a Hitachi HU-12 electron microscope. Tissues for light microscopic examination were embedded in paraffin, cut in cross sections 4 $\mu \mathrm{m}$ thick, and stained with hematoxylin-eosin, Weigert's resorcin-fuchsin, alcian blue ( $\mathrm{pH}$ 2.5) and oil red 0.

Received for publication, January 17, 1984. 


\section{Result and Discussion}

Histological observations by $\mathrm{Cucu}$ (1977) indicated that intimal fibromuscular thickening was noted in aortas from turtles of the genus Emis orbicularis, but not in those from turtles of genus Testudo graeca iberia pallas. Fibromuscular intimal thickening was also observed in six month-old green sea turtles (genus, Chelonia mydas), but it was not obvious in three year-old fresh water turtles (genus, Pseudemys) (Toda et al. 1984). The majority of cells in the thickened intima of the aorta from marine turtles were identified as smooth muscle cells by the presence of fusiform dense bodies, pinocytotic vesicles and basement membranes (Fig. 1). These smooth muscle cells were morphologically similar to those of other animals (Geer and Haust 1972). The minority of cells were macrophages and granulocytes. Eight of the thirteen green sea turtles examined had aneurysmal dilatations and multiple raise grayish-white plaques in the common aorta and thoracic aorta. These lesions were characterized by disruption of the elastic fibers and varying degrees of mucopolysaccharide deposition in the media (Fig. 2). Capillary proliferation was prevalent in such hypocellular media and stained heavily with alcian blue (Fig. 2). No significant lipid deposition was demonstrated by oil red-O stain. Most of the medial smooth muscle cells displayed organelle degeneration, shrunken cytoplasms and cytoplasmic projections (Fig. 3). These types of cell degeneration differed from total cell death and focal cytoplasmic necrosis. (Toda et al. 1981, 1983) These aneurismic lesions were similar to those found in Marfan's syndrome in human and also in copper deficiencies and $\beta$-aminopropionitrile treatments in animals (Simpson et al. 1980).

It is necessary to determine whether a copper deficiency contributed to the

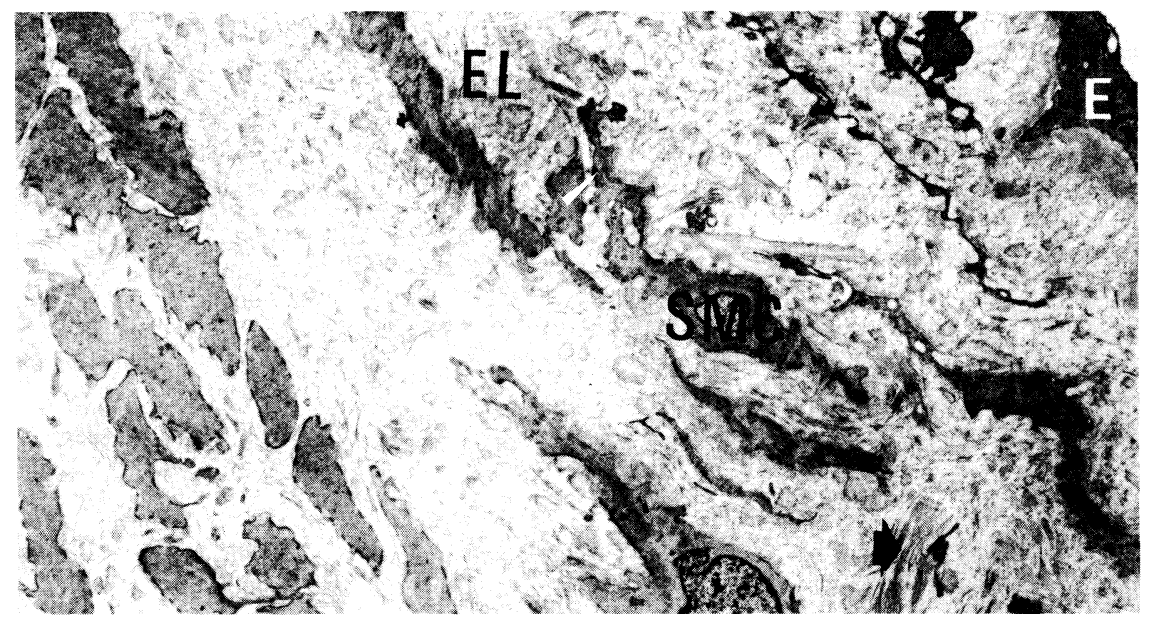

Fig. 1. Spindle-shaped smooth muscle cells (SMC), collagen fibers (arrow) and tiny elactic fibers $(\mathrm{EL})$ are present in the tickened aortic intima. $(\times 2,800)$ $\mathrm{E}$, endothelial cell. 

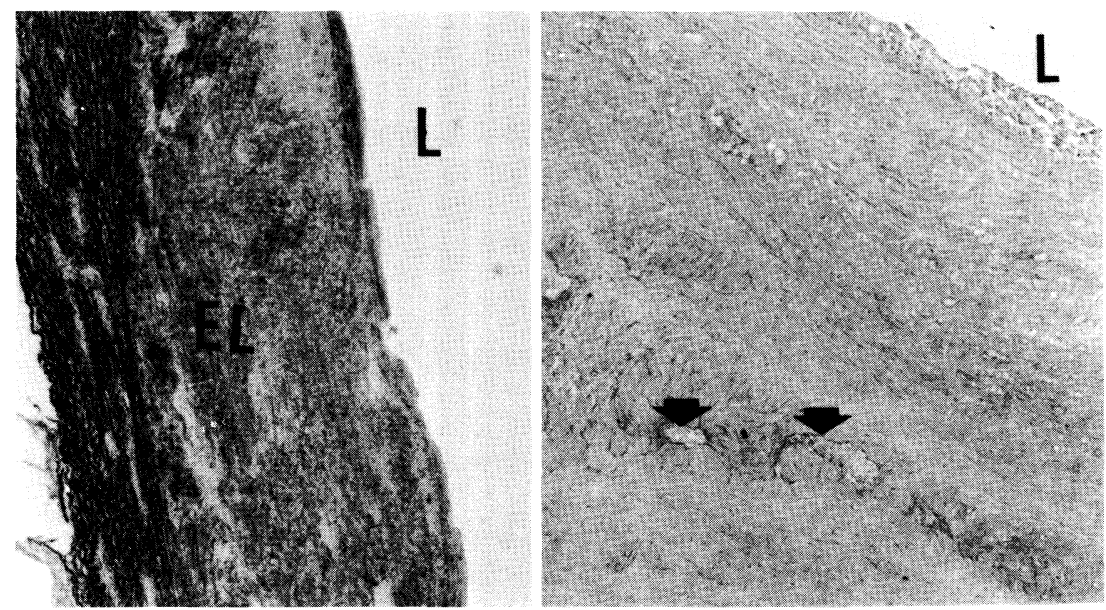

Fig. 2. Note the flea-bitten appearance of the medial elastic fibers (EL) on the left side, as shown by Weigert's resorcin fuchsin stain. $(\times 40)$.

Capillary proliferation (arrow) in a mucopolysacharide-rich area is apparent on the right side, as shown by alcian blue stain. $(\times 100)$ L, luminal side.

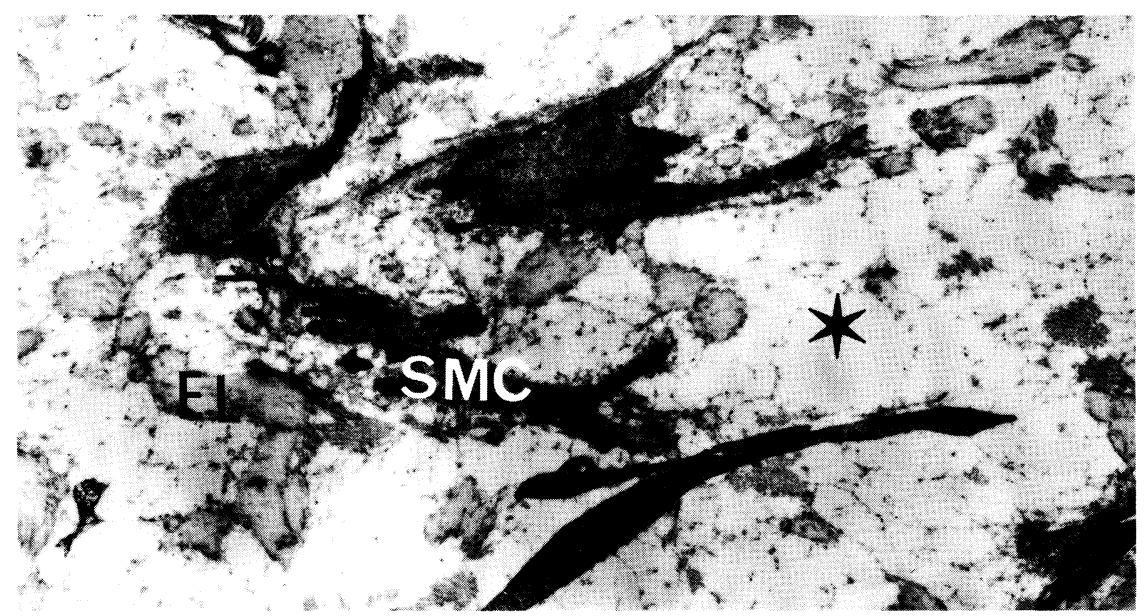

Fig. 3. The shrunken smooth muscle cells (SMC) with cytoplasmic projections and thin elastic fibers (EL) are seen in a pool of amorphous materials, probably rich in mucopolysaccharides (star). $(\times 8,700)$

aneurysm, because these turtles were raised and kept in a geographic location that is known to be deficient in mineral copper. (Maynard and Loosli 1969) However, other environmental factors, including exposure to salinity, could not be excluded.

\section{References}

1) Cucu, F.L. (1977) Aortic intimal thickenings in tortoise. Rev. Roum. Med. Med. Int., 15 (4), 411-414. 
2) Geer, J.C. \& Haust, M.D. (1972) Smooth muscle cells in atherosclerosis. In: Monographs on Atherosclerosis, edited by O.J. Pollak, H.S. Simms \& J.E. Kirks, Karger, Basal, pp. 39-59.

3) Maynard, L.A. \& Loosli, J.K. (1969) Animal Nutrition, McGraw-Hill, New York, p. 190.

4) Simpson, C.F., Boucek, R.J. \& Noble, N.L. (1980) Similarity of aortic pathology in Marfan's Syndrome, copper deficiency in chicks and $\beta$-aminopropionitrile toxicity in turkeys. Exp. mol. Path., 32, 81-90.

5) Toda, T., Leszczynski, D.E. \& Kummerow, F.A. (1981) Degenerative changes in endothelial and smooth muscle cells from aging swine ductus arteriosus and venosus. Amer. J. Anat., 160, 37-49.

6) Toda, T., Leszczynski, D.E. \& Kummerow, F.A. (1983) The role of 25-hydroxyvitamin $\mathrm{D}_{3}$ in the induction of atherosclerosis in swine and rabbit by hypervitaminosis D. Acta path. jap., 33, 37-44.

7) Toda, T., Toda, Y. \& Kummerow, F.A. (1984) Electron microscopic comparison of the tunica media of the thoracic aorta between species. Tohoku J. exp. Med., 143, $141-147$. 